Review

\title{
Autobiographical memory, the ageing brain and mechanisms of psychological interventions
}

\author{
Andrew P. Allen, Caoilainn Doyle, Seán Commins, Richard A.P. Roche* \\ Department of Psychology, Maynooth University, Co. Kildare, Ireland
}

\section{A R T I C L E I N F O}

\section{Keywords:}

Memory

Executive function

Ageing

Dementia

Reminiscence therapy

\begin{abstract}
A B S T R A C T
Elucidating the impact of healthy cognitive ageing and dementia on autobiographical memory (AM) may help deepen our theoretical understanding of memory and underlying neural changes. The distinction between episodic and semantic autobiographical memory is particularly informative in this regard. Psychological interventions, particularly those involving reminiscence or music, have led to differential effects on episodic and semantic autobiographical memory. We propose that executive function is a key mediator of psychological therapies on autobiographical memory. We also highlight that interventions that alleviate stress and improve mood, including in major depression, can enhance autobiographical memory. Future research employing more longitudinal approaches and examining moderating factors such as gender and education level will deepen our understanding of changes in AM in later life, enhance our theoretical understanding of the neuroscience of AM and ageing, and help to develop better targeted interventions for preserving AM in older adults.
\end{abstract}

\section{Introduction}

Memory concerning an individual's own life (autobiographical memory; AM) comprises multiple forms of long-term memory (e.g. Nyberg and Tulving, 1996). AM can be divided into episodic memory (memory for specific events from one's own past; for example, an unexpected visit from an old friend) and semantic memory (memory of general knowledge of one's own past; for example, the name of the school one attended). AM with greater episodic richness will contain greater level of detail and a greater subjective re-experiencing of aspects of the event, such as emotions, thoughts, vivid visual imagery and the individual's location in space (Irish et al., 2008). The emotional context is likely associated with the amygdala, and vividness of AM is likely linked to processing in the visual cortices (Cabeza and St. Jacques, 2007), although vividness in other sense modalities may be linked to other brain regions (e.g. auditory cortices).

Episodic AM in particular can decline in healthy ageing compared to semantic AM (Piolino et al., 2002), and there is more marked degradation of AM in mild cognitive impairment (MCI; Murphy et al., 2008; Leyhe et al., 2009) and dementia (see review by Piolino et al., 2009). AM is tightly interwoven with our sense of continuous self and identity (e.g. Conway and Pleydell-Pearce, 2000; Prebble et al., 2013; Wilson and Ross, 2003). Despite evidence that there is some preservation of a sense of self in dementia, loss of AM can have negative implications for selfhood; this in turn can impact upon how people with dementia relate to family and friends and the extent to which they cope with dementia, which in turn impacts upon their quality of life (Caddell and Clare, 2010; Duval et al., 2012). In addition to the global health burden of dementia (Prince, 2015), and associated problems such as major depression (World Health Organization, 2017), there is evidence that AM dysfunction in people with dementia can have a negative impact on their carers. For example, Kumfor et al. (2016) have shown that loss of recent AM in people with Alzheimer's disease (AD) was associated with worsened psychological well-being in carers.

AM is vulnerable not only to loss of true memories, but also recall of false memories that have never actually occurred in one's past. People may become more prone to false memories as they age, perhaps due to frontal mechanisms such as source monitoring (e.g. Schacter et al., 1997). There is some evidence that people with $\mathrm{AD}$ produce more false memories for recent AM than healthy aged participants (Cooper et al., 2006), although the test in this study used a short story generated by the participants, so the level of autobiographical relevance may not be as great for other AM. Recall of false AM may also be due to motivated confabulation in people with frontal lobe damage, perhaps to create more emotionally positive AM (e.g. Conway and Tacchi, 1996). Even in healthy research participants, imagining an event occurring in early life can increase estimated probability of the event having occurred in early life (Pezdek et al., 2006), and even induce false AM (Mazzoni and Memon, 2003).

Given this burden on patients and carers, it is vital that we gain a

\footnotetext{
* Corresponding author. Department of Psychology, John Hume Building, Maynooth University, Co. Kildare, Ireland.

E-mail addresses: Andrew.Allen@mu.ie (A.P. Allen), Caoilainn.Doyle@mu.ie (C. Doyle), Sean.Commins@mu.ie (S. Commins), Richard.Roche@mu.ie (R.A.P. Roche).
} 
greater understanding of the cognitive impact of interventions that might serve to mitigate the impact of dementia. An understanding of the cognitive and emotional mechanisms that drive preservation of AM will allow for interventions to be better tailored to target these mechanisms. Furthermore, functional neuroimaging of AM may deepen our understanding of complex AM retrieval processes (e.g. the recruitment of different brain regions during different phases of AM; see St Jacques, 2012, for a review), and can thus help to deepen our understanding of the mechanisms driving interventions that may improve AM.

In this review, we critically discuss the effect of healthy brain ageing and dementia on AM, highlighting their differential impact on episodic and semantic AM and associated brain regions, as well as the theoretical implications of these findings. We discuss psychological interventions to improve AM (particularly reminiscence therapies and music) and potential cognitive and emotional mechanisms that may explain the positive effects of these interventions. Finally, we suggest future directions for this area of research.

\section{Autobiographical memory, ageing and dementia}

\subsection{Autobiographical memory, ageing and neural underpinnings}

AM is a complex, multimodal form of cognition that involves functional input from various regions of the brain (e.g. Rubin, 2005). Meta-analyses (using data sources from a range of age groups) have offered support for an AM network involving temporal, parietal, medial and ventrolateral prefrontal regions, as well as occipital regions, posterior cingulate cortices and the cerebellum (Spreng et al., 2009; Svoboda et al., 2006). Activation of certain regions in the brain may enhance the phenomenology of re-experiencing the autobiographical episode; occipital regions and the cuneus/precuneus are involved in visual imagery (Greenberg and Rubin, 2003; Hebscher et al., in press) while the amygdala mediates emotional processing (e.g. LaBar and Cabeza, 2006). There is evidence that episodic and semantic AM are associated with different patterns of neural activation; semantic with right inferior temporal gyrus and left thalamus; and episodic with the left precuneus, left superior parietal lobule, right cuneus (Addis et al., 2004), left hippocampus, and left temporal pole (Maguire and Mummery, 1999). Spreng et al. (2009) further suggested functional overlap between AM and other cognitive functions, particularly theory of mind (i.e. intuitive understanding of other people's and one's own cognition). Spreng and Grady (2010) provided interesting evidence (from young adults) suggesting that midline structures of the default mode network (DMN), responsible for stimulus-independent thought, are involved in cued AM as well as prospection (i.e. thinking about the future). There is also overlap in neural activation in response to cognitive tasks which may represent both AM and other cognitive processes such as executive function (Svoboda et al., 2006; Duncan and Owen, 2000; see Section 3.2. for further discussion of executive function and AM).

In addition to the episodic/semantic distinction, the age of memories has implications for the neural underpinnings of AM. Remote memories (10 years old) were particularly well represented in the ventromedial prefrontal cortex (vmPFC) compared to recent memories in young adults, and remote memories were better represented within the posterior hippocampus, whereas in the anterior hippocampus there was no such difference between recent and remote memories (Bonnici et al., 2012). At a two-year follow-up, the recent memories (now more remote) were better represented in the vmPFC than they had been at baseline (Bonnici and Maguire, in press). There is also an interaction between episodicity of AM and the age of the memory: a greater deterioration in episodic detail holds for length of retention interval (Piolino et al., 2002). In Fig. 1, we outline brain regions proposed to be implicated in AM function.

In rats, a recent study (Barry et al., 2016) has shown that activity of the medial prefrontal cortex (infralimbic, prelimbic and anterior cingulate cortex) during retrieval of a spatial task increased in correspondence with the age of the memory, reaching significance between 14 and 30 days. In contrast, neural activity of the hippocampus remained largely unchanged across retention intervals, suggesting an ongoing role for the hippocampus in both recent and remote memories (see Winocur et al., 2010a for debate on this issue). While episodic memory in animals is difficult to discern, there is evidence that some animals display episodic-like memories. For example, Clayton and Dickinson (1998) were the first to demonstrate that Western scrub jays (Aphelocoma californica) could recall not only the location of cached food but when the food was stored. Episodic memory has recently been tested in the laboratory using a What-Where-When/Which task (Eacott and Norman, 2004). Animals in this task are required to associate a particular object (what) with a particular location (where) within a certain visuo-spatial context (when); such a task is also hippocampaldependent (Langston and Wood, 2010). Furthermore, Davis et al. (2013) have shown that aged mice (12 months) are particularly impaired on this task, mirroring age-related decline in episodic memory observed in humans (Ramsøy et al., 2012). Similar to the suggestion that the preservation of remote memories in older adult humans may be due to the recollection of non-specific rather than detailed episodic-like information, older animals also show preserved remote spatial memories that are thought to rely on a more schematic representation of the environment (Winocur et al., 2010b).

The hemispheric asymmetry reduction in older adults model (HAROLD; Cabeza, 2002) posits that for a given task, older adults will display less lateralisation of neural activation than younger adults. Consistent with the HAROLD model, bilateral hippocampal activation in older adults was observed during autobiographical event retrieval compared to left hippocampal activation in younger adults (Maguire and Frith, 2003), although the two groups had comparable activation during semantic memory retrieval. Similarly, Reuter-Lorenz and Cappell (2008) discuss a compensation related utilisation of neural circuits hypothesis (CRUNCH), with older adults indicating a greater level of activation in specific brain regions despite performing at a similar level to younger adults behaviourally. For example, the dorsal anterior cingulate cortex was more activated during semantic memory in older adults, compared to greater activation during episodic memory in younger adults (Martinelli et al., 2013a), which could be a compensatory mechanism allowing for relatively preserved semantic AM in older adults. As the dorsal anterior cingulate cortex is also involved in executive function (e.g. Shenhav et al., 2013), this could represent a form of cognitive reserve in a region that regulates both executive function and semantic AM. Consistent with such compensatory models of ageing, there is electrophysiological evidence that older adults who are cognitively impaired compared to age-matched controls show enhanced late positivities (P300) during both encoding and recognition stages of a cued learning task (Gallen et al., unpublished data).

Although models such as CRUNCH suggest comparable performance may belie underlying neurological differences, there is also behavioural evidence of differences in AM performance in older adults. In developing the relatively open-ended autobiographical interview, cross-sectional evidence indicated a shift towards more semantic details over episodic detail with ageing (Levine et al., 2002). Compared to younger adults, both healthy older adults and people with dementia had poorer episodic AM, although all three groups performed comparably at autobiographical semantic memory (Martinelli et al., 2013b). People with AD (but not healthy older adults) were impaired compared to young adults for autobiographical episodic memories that were important to their sense of self; these researchers required participants to think of these "self-defining memories", which were memories that "could help to explain who one is as an individual" (p. 71, Martinelli et al., 2013b).

More semanticized AM in older adults has recently been associated with greater coupling between the default network and lateral prefrontal cortex (as assessed with resting state fMRI); such default- 


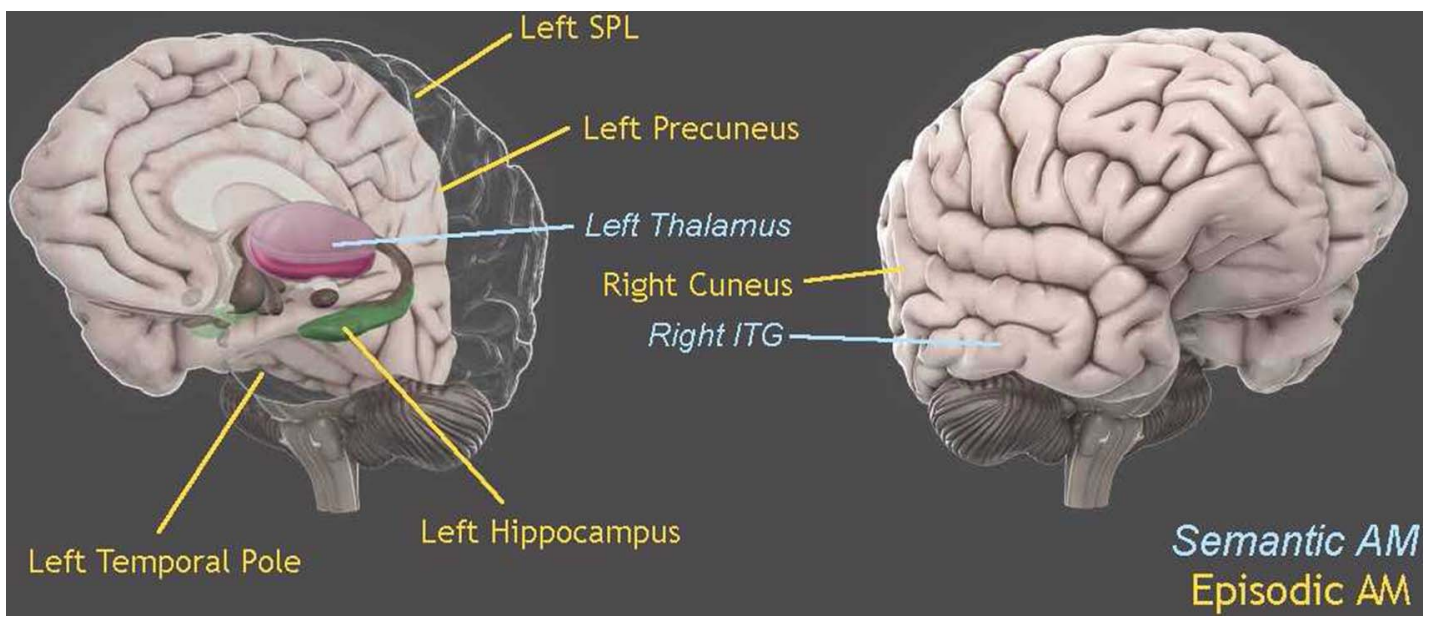

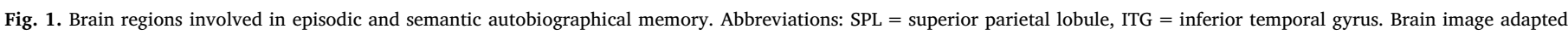
from Genes to Cognition Online (www.g2conline.org), copyright Cold Spring Harbor Laboratory.

executive coupling has also been posited as a neural mechanism for more general age-related increases in reliance on "crystalized" as opposed to "fluid" cognitive processes (Spreng et al., in press). Nonetheless, the shift towards reduced episodic detail should be interpreted with care, particularly when using open-ended scales without probes to examine episodic AM, as this shift may represent a motivated change in behaviour in older adults as well as (or even instead of) a shift in specific memory ability (Fitzgerald and Broadbridge, 2012). Such a motivated change in memory retrieval would likely rely on executive processes, such as memory search strategies.

\subsection{Autobiographical memory and dementia}

Dementia can impair AM, affecting both retrograde and anterograde amnesia (see review on AD by El Haj et al., 2015). However, dementia is also a heterogeneous syndrome which can be due to different disease states, with differing cognitive profiles. A provocative example of this is evidence that the "temporal gradient" in the impact of dementia may work in opposite directions depending upon diagnosis, with AD being associated with poorer recent AM and semantic dementia with poorer remote AM (Kopelman et al., 1989; Snowden et al., 1996, although cf. Dall'Ora et al., 1989; Irish et al., 2011). Further evidence of diagnosisspecific effects come from a study at one-year follow-up; AM performance correlated strongly with level of lateral temporal lobe integrity in people with $\mathrm{AD}$, whereas in other patients, either with semantic dementia or with behavioural variant frontotemporal dementia (FTD), recent AM disruption was attributable to cortical thinning in posterior regions, including the posterior cingulate cortex (Irish et al., in press).

People with frontotemporal dementia were found to have reduced sense of reliving AM and of self-perspective during retrieval, and PET imaging indicated that AM deficits were associated with reduced glucometabolic activity in left orbitofrontal and temporal neocortical areas (Piolino et al., 2007). People with frontotemporal and mixed frontotemporal/semantic dementia generated less episodically rich AM, with the mixed group generating excessive generic semantic detail in AM, whereas people with progressive nonfluent aphasia (PNFA) had some episodic AM impairment; structured cueing alleviated the impairment in PNFA but not the other patient groups (McKinnon et al., 2008).

The contrast between $\mathrm{AD}$ and semantic dementia in particular can inform the debate concerning the role of the hippocampus and the neocortex in $\mathrm{AM}$, as $\mathrm{AD}$ is associated with damage to mediotemporal regions such as the hippocampus early in the disorder (Braak and Braak, 1991), whereas semantic dementia is associated with greater damage to neocortical as opposed to mediotemporal regions (Graham and Hodges, 1997). It has been suggested that the time course of memory loss in AD may be more consistent with Cortical Reallocation Theory (Alvarez and Squire, 1994), which posits that while the hippocampus is important for consolidation, long-term storage of AM occurs in the neocortex, so hippocampal damage should have a greater effect on more recent memories, leading to a temporal gradient. By comparison, Multiple Trace Theory (Nadel and Moscovitch, 1997) proposes the involvement of a broader range of brain regions in AM storage. According to Multiple Trace Theory, different brain structures are used for the retrieval of episodic versus semantic AM, with episodic memories in particular being associated with an interaction between hippocampal and neocortical regions, whereas retrieval of semantic AM is more associated with neocortical activation. Further support for the multiple trace theory has come from evidence of more marked episodic $\mathrm{AM}$ impairment in $\mathrm{AD}$ (which is associated with early damage to mediotemporal regions) and clearer semantic AM impairment in mild semantic dementia (which is associated with greater neocortical damage) (Ivanoiu et al., 2006).

Recent evidence (Kitamura et al., 2017) using optogenetic techniques in mice has suggested that a memory trace is laid down in the prefrontal cortex immediately and becomes fully functional with time. In contrast, hippocampal memory traces become silent with time. Despite this silencing, hippocampal neurons may still be involved in the recall of remote memories, especially those with episodic details (Frankland and Bontempi, 2005). Although models in mice do not clearly differentiate between semantic and episodic memories, a number of $\mathrm{AD}$ models including Tg2576APP $\mathrm{SWE}_{\mathrm{SWE}}$ and 3XTgAD have shown clear episodic-like memory impairments in the What-WhereWhen/Which task (Good et al., 2007; Davis et al., 2013). For example, Davis et al. (2013) demonstrated that 3XTgAD mice (that develop progressive Amyloid-beta and tau pathology in hippocampal and cortical structures) show severe episodic memory impairment at both 6 and 12 months of age; these deficits occur more rapidly than agematched controls.

\section{Interventions}

\subsection{Impact of psychological interventions}

Although much research in ageing and AM comprises cross-sectional comparison between older and younger adults, intervention research with aged participants may offer a greater insight into causal mechanisms for changes in AM. Given more general evidence that cognitive training can benefit cognition in healthy ageing (Kelly et al., 2014) and dementia (Sitzer et al., 2006, but cf. Bahar-Fuchs et al., 2013), it is of interest whether psychological interventions, particularly 
Table 1

Impact of psychological interventions on AM in older adults.

\begin{tabular}{|c|c|c|c|c|c|}
\hline Paper & Intervention & Participants & $\begin{array}{l}\text { Clinical } \\
\text { condition } \\
\end{array}$ & 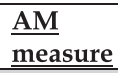 & $\begin{array}{l}\text { Intervention } \\
\text { effect on AM }\end{array}$ \\
\hline $\begin{array}{l}\text { Woods et al. } \\
\text { (2016) }\end{array}$ & $\begin{array}{l}\text { Reminiscence } \\
\text { therapy (RT) } \\
\text { v. standard } \\
\text { care control }\end{array}$ & $\begin{array}{l}\text { RT: }(\mathrm{N}=268): \text { Mean } \\
\text { age }=77.5, \mathrm{SD}=7.3, \\
\hat{\jmath}=53 \%, \circ=47 \% \\
\text { Control: }(\mathrm{N}=219): \\
\text { Mean age }=77.3, \mathrm{SD} \\
=7.2, \delta=48 \%, \uparrow= \\
52 \%\end{array}$ & $\begin{array}{l}\text { Mild- } \\
\text { moderate } \\
\text { dementia }\end{array}$ & AMI & $\begin{array}{l}\text { No overall effect; } \\
\text { compliance } \\
\text { (sessions } \\
\text { attended) } \\
\text { associated with } \\
\uparrow A M\end{array}$ \\
\hline $\begin{array}{l}\text { Melendez et } \\
\text { al. (2015) }\end{array}$ & $\begin{array}{l}\text { Reminiscence } \\
\text { therapy (RT) } \\
\text { v. standard } \\
\text { care control }\end{array}$ & 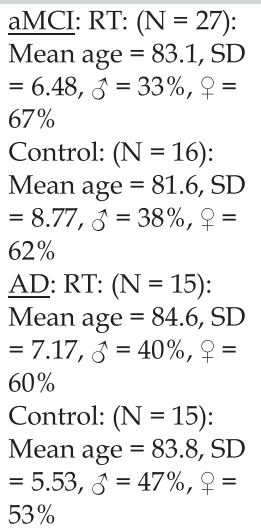 & $\begin{array}{l}\text { Amnestic } \\
\text { mild cognitive } \\
\text { impairment } \\
\text { (aMCI) or AD }\end{array}$ & AMI & $\begin{array}{l}\text { aMCI: } \uparrow \text { episodic } \\
\text { AM, } \\
\uparrow \text { semantic AM } \\
\text { AD: } \uparrow \text { episodic } \\
\text { AM }\end{array}$ \\
\hline $\begin{array}{l}\text { Lopes et al. } \\
(2016)\end{array}$ & $\begin{array}{l}\text { Simple } \\
\text { reminiscence } \\
\text { therapy } \\
(\text { SRT) v. } \\
\text { standard care } \\
\text { control }\end{array}$ & $\begin{array}{l}\text { SRT }(\mathrm{N}=20) \text { : Mean } \\
\text { age }=83.9, \mathrm{SD}= \\
6.99, \hat{\jmath}=25 \%, \uparrow= \\
75 \% \\
\text { Control }(\mathrm{N}=21) \text { : } \\
\text { Mean age }=83.6, \mathrm{SD} \\
=8.35, \hat{\jmath}=23.8 \%, \text { ㅇ } \\
=76.2 \%\end{array}$ & $\begin{array}{l}\text { Cognitive } \\
\text { impairment } \\
\text { (MoCA score } \\
\text { of 9-26) }\end{array}$ & AMT & $\begin{array}{l}\uparrow \text { episodic AM, } \\
\downarrow \text { latency to AM, } \\
\text { more positive } \\
\text { and less negative } \\
\text { valence in AM }\end{array}$ \\
\hline $\begin{array}{l}\text { Morgan } \\
(2000)\end{array}$ & $\begin{array}{l}\text { Life review v. } \\
\text { no treatment } \\
\text { control }\end{array}$ & 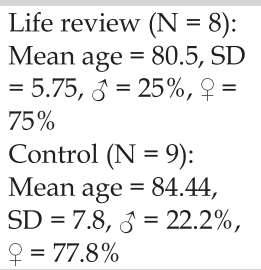 & $\begin{array}{l}\text { Mild- } \\
\text { moderate } \\
\text { dementia }\end{array}$ & AMI & $\begin{array}{l}\uparrow \text { Semantic AM, } \\
\text { no effect episodic } \\
\text { AM }\end{array}$ \\
\hline $\begin{array}{l}\text { Serrano et al. } \\
(2004)\end{array}$ & $\begin{array}{l}\text { Life review v. } \\
\text { TAU control }\end{array}$ & $\begin{array}{l}\text { Life review }(\mathrm{N}=20) \text { : } \\
\text { Mean age }=75.8, \mathrm{SD} \\
=8.1 \\
\hat{\sigma}=17.4 \%, q=82.6 \% \\
\text { Control }(\mathrm{N}=23): \\
\text { Mean age }=78.4, \mathrm{SD} \\
=7.3\end{array}$ & $\begin{array}{l}\text { Depression, } \\
\text { no dementia }\end{array}$ & AMT & $\uparrow$ episodic AM \\
\hline
\end{tabular}

(continued on next page 
Table 1 (continued)

\begin{tabular}{|c|c|c|c|c|c|}
\hline & & $\hat{o}=30 \%, q=70 \%$ & & & \\
\hline $\begin{array}{l}\text { Gonçalves et } \\
\text { al. (2009) }\end{array}$ & $\begin{array}{l}\text { Life review v. } \\
\text { control }\end{array}$ & $\begin{array}{l}\text { Life review }(\mathrm{N}=22) \text { : } \\
\text { Mean age }=80.7, \mathrm{SD} \\
=4.5, \text { 우 }=100 \%\end{array}$ & $\begin{array}{l}\text { Depression, } \\
\text { no dementia }\end{array}$ & AMT & $\begin{array}{l}\uparrow \text { positive and } \\
\text { episodic AM }\end{array}$ \\
\hline $\begin{array}{l}\text { Subramania } \\
\mathrm{m} \text { et al. } \\
(2014)\end{array}$ & $\begin{array}{l}\text { Life review } \\
\text { and co- } \\
\text { creating life } \\
\text { story book v. } \\
\text { control: } \\
\text { receiving life } \\
\text { story book } \\
\text { created by } \\
\text { relatives }\end{array}$ & $\begin{array}{l}\text { Life review }(\mathrm{N}=12) \text { : } \\
\text { Mean age }=84.5, \mathrm{SD} \\
=6.7, \hat{\jmath}=27.3 \%, \stackrel{+}{=}= \\
72.7 \% \\
\text { Control }(\mathrm{N}=12) \text { : } \\
\text { Mean age }=88.3, \mathrm{SD} \\
=6, \hat{0}=33.3 \%, \stackrel{+}{=}= \\
66.7 \%\end{array}$ & $\begin{array}{l}\text { Mild- } \\
\text { moderate } \\
\text { dementia }\end{array}$ & AMI & $\begin{array}{l}\text { Life review: } \uparrow \\
\text { episodic and } \\
\text { semantic memory }\end{array}$ \\
\hline $\begin{array}{l}\text { Lalanne et al. } \\
\text { (2015) }\end{array}$ & $\begin{array}{l}\text { REMau } \\
\text { program } \\
\text { (episodic and } \\
\text { semantic AM } \\
\text { retrieval) v. } \\
\text { control } \\
\text { (cognitive } \\
\text { training) }\end{array}$ & $\begin{array}{l}\text { REMau }(\mathrm{N}=16) \text { : } \\
\text { Mean age }=71.4, \mathrm{SD} \\
=8.8 \\
\text { Control }(\mathrm{N}=17) \text { : } \\
\text { Mean age = 73.1, } \\
\mathrm{SD}=6.9\end{array}$ & $\begin{array}{l}\text { Mild- } \\
\text { moderate AD }\end{array}$ & $\begin{array}{l}\text { Semantic } \\
\text { AM: } \\
\text { (questions } \\
\text { on } \\
\text { acquaintanc } \\
\text { es, } \\
\text { school/wor } \\
k \text { life, } \\
\text { leisure } \\
\text { activity) } \\
\text { Episodic } \\
\text { AM: } \\
\text { TEMPau } \\
\text { task }\end{array}$ & $\begin{array}{l}\uparrow \text { episodic and } \\
\text { semantic AM in } \\
\text { TEMPau group, } \\
\text { more pronounced } \\
\text { for semantic }\end{array}$ \\
\hline $\begin{array}{l}\text { De Medeiros } \\
\text { et al. (2011) }\end{array}$ & $\begin{array}{l}\text { AWW v. } \\
\text { REM v. no } \\
\text { treatment }\end{array}$ & 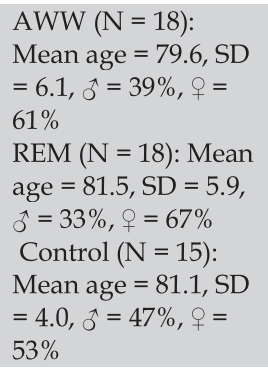 & No dementia & $\begin{array}{l}\text { AMI, } \\
\text { RMWAT }\end{array}$ & $\begin{array}{l}\text { No effect on AM } \\
\text { performance; } \\
\text { more positive } \\
\text { valence AM }\end{array}$ \\
\hline $\begin{array}{l}\text { El Haj \& } \\
\text { Antoine } \\
(2017)\end{array}$ & $\begin{array}{l}\text { Self- } \\
\text { description v. } \\
\text { text reading }\end{array}$ & 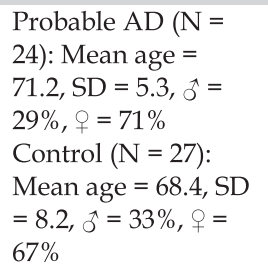 & $\begin{array}{l}\text { Probable AD, } \\
\text { healthy older } \\
\text { adults }\end{array}$ & $\begin{array}{l}\text { Single event } \\
\text { in life } \\
\text { recalled in } \\
\text { detail }\end{array}$ & $\begin{array}{l}\uparrow \text { specificity, } \\
\text { context recall and } \\
\text { reliving in } \\
\text { probable AD. } \\
\uparrow \text { context recall in } \\
\text { control }\end{array}$ \\
\hline $\begin{array}{l}\text { Ramírez et al. } \\
\text { (2014) }\end{array}$ & $\begin{array}{l}\text { MAPEG } \\
\text { program } \\
\text { (forgiveness, } \\
\text { gratitude, life }\end{array}$ & $\begin{array}{l}\text { MAPEG }(\mathrm{N}=26): \hat{0} \\
=38 \%, \text { }=62 \% \\
\text { Placebo }(\mathrm{N}=20): \hat{\jmath} \\
=35 \%, \text { ㅇ }=65 \%\end{array}$ & No dementia & AMT & $\uparrow$ episodic AM \\
\hline
\end{tabular}

(continued on next page 
Table 1 (continued)

\begin{tabular}{|c|c|c|c|c|c|}
\hline & $\begin{array}{l}\text { review) v. } \\
\text { placebo }\end{array}$ & $\begin{array}{l}\text { Mean age }=71.2, S D \\
=7.1\end{array}$ & & & \\
\hline $\begin{array}{l}\text { Irish et al. } \\
(2006)\end{array}$ & $\begin{array}{l}\text { Classical } \\
\text { music v. } \\
\text { "silence" } \\
\text { control } \\
\text { (repeated } \\
\text { measures) }\end{array}$ & $\begin{array}{l}\mathrm{AD}(\mathrm{N}=10): \text { Mean } \\
\text { age }=76.3, \mathrm{SD}=7.5, \\
\hat{o}=60 \%, \circ=40 \% \\
\text { Healthy control }(\mathrm{N} \\
=10): \text { Mean age }= \\
76.5, \mathrm{SD}=5.2, \delta= \\
50 \%, \circ=50 \%\end{array}$ & $\begin{array}{l}\text { Mild AD, } \\
\text { Healthy } \\
\text { control }\end{array}$ & AMI & $\begin{array}{l}\uparrow \text { episodic and } \\
\text { semantic AM in } \\
\text { people with AD. } \\
\text { No effect in } \\
\text { healthy control }\end{array}$ \\
\hline $\begin{array}{l}\text { Foster \& } \\
\text { Valentine } \\
(2001)\end{array}$ & $\begin{array}{l}\text { Auditory } \\
\text { stimulation } \\
\text { (familiar } \\
\text { music, novel } \\
\text { music, } \\
\text { cafeteria } \\
\text { noise, quiet) }\end{array}$ & $\begin{array}{l}\mathrm{N}=29, \text { Mean age }= \\
78.7, \text { range }=68-90\end{array}$ & $\begin{array}{l}\text { Mild- } \\
\text { moderate/ } \\
\text { moderate } \\
\text { dementia }\end{array}$ & $\begin{array}{l}\text { Semantic- } \\
\text { type AM } \\
\text { questions } \\
\text { derived } \\
\text { from MMSE }\end{array}$ & $\begin{array}{l}\uparrow \mathrm{AM} \text { (remote } \\
\text { and medium- } \\
\text { remote but not } \\
\text { recent } \mathrm{AM} \text { ) for } \\
\text { music }\end{array}$ \\
\hline $\begin{array}{l}\text { García et al. } \\
\text { (2011) }\end{array}$ & $\begin{array}{l}\text { Music } \\
\text { (happy, sad } \\
\text { or neutral } \\
\text { emotion), } \\
\text { ambient } \\
\text { noise, no } \\
\text { sound }\end{array}$ & $\begin{array}{l}\mathrm{N}=25, \text { Mean age }= \\
80.7, \mathrm{SD}=5.8\end{array}$ & $\begin{array}{l}\text { Probable AD } \\
\text { (mean MMSE } \\
=14.6)\end{array}$ & $\begin{array}{l}\text { Semantic- } \\
\text { type AM } \\
\text { questions } \\
\text { derived } \\
\text { from MMSE } \\
\text { (same as } \\
\text { Foster \& } \\
\text { Valentine, } \\
\text { 2001) }\end{array}$ & $\begin{array}{l}\text { Sad music } \uparrow \\
\text { remote AM }\end{array}$ \\
\hline $\begin{array}{l}\text { Särkämö et } \\
\text { al. (2013) }\end{array}$ & $\begin{array}{l}\text { Singing } \\
\text { group, music } \\
\text { listening } \\
\text { group v. } \\
\text { usual care } \\
\text { control group }\end{array}$ & $\begin{array}{l}\text { Singing }(\mathrm{N}=27) \text { : } \\
\text { Mean age }=78.5, \mathrm{SD} \\
=10.4, \widehat{\jmath}=41 \%, \%= \\
59 \% \\
\text { Listening }(\mathrm{N}=29) \text { : } \\
\text { Mean age }=79.4, \\
\mathrm{SD}=10.1, \widehat{\jmath}=10 \%, \\
q=90 \% \\
\text { Control }(\mathrm{N}=28) \text { : } \\
\text { Mean age }=78.4, \mathrm{SD} \\
=11.6, \widehat{\jmath}=36 \%, q= \\
64 \% \%\end{array}$ & $\begin{array}{l}\text { Mild- } \\
\text { moderate } \\
\text { dementia }\end{array}$ & $\begin{array}{l}\text { Modified } \\
\text { version of } \\
\text { autobiograp } \\
\text { hical } \\
\text { fluency task } \\
\text { (Dritschel et } \\
\text { al., 1992) }\end{array}$ & $\begin{array}{l}\text { Music conditions: } \\
\uparrow \text { remote AM at 6- } \\
\text { month follow-up }\end{array}$ \\
\hline $\begin{array}{l}\text { El Haj et al. } \\
(2013)\end{array}$ & $\begin{array}{l}\text { Favourite } \\
\text { music v. } \\
\text { silence }\end{array}$ & $\begin{array}{l}\mathrm{AD}(\mathrm{N}=18): \text { Mean } \\
\text { age }=75.8, \mathrm{SD}=5.8, \\
\hat{o}=33 \%, \circ=66 \% \\
\text { Healthy control }(\mathrm{N} \\
=18): \text { Mean age }= \\
73.6, \mathrm{SD}=6.3, \delta= \\
61 \%, \circ=39 \%\end{array}$ & $\mathrm{AD}$ & $\begin{array}{l}\text { TEMPau } \\
\text { task }\end{array}$ & $\begin{array}{l}\uparrow \text { grammatical } \\
\text { density and } \\
\text { propositional } \\
\text { density in AM }\end{array}$ \\
\hline
\end{tabular}

Key: AMI = autobiographical memory interview (Kopelman et al., 1989), AMT = autobiographical memory test (Williams and Broadbent, 1986), AWW = Autobiographical writing workshop, MAPEG = program of forgiveness, gratiude and life review (Ramírez et al., 2014), REM = oral reminiscence, RMWAT = remote memory word associations task, SRT = simple reminiscence therapy, TAU = treatment-as-usual, TEMPau = Test épisodique de mémoire du passé (Piolino et al., 2006; Piolino et al., 2000). Särkämö et al. used a modified version of the autobiographical fluency task (Dritschel et al., 1992). For clinical condition, "dementia" indicates that form of dementia was not specified.

those targeting AM directly, can improve AM.

Reminiscence therapy/life review has been recognised as an area of overlapping interest for cognitive psychologists studying AM and for clinical psychologists interested in the application of AM for mental health (Webster and Cappeliez, 1993), and represents a potential means for improving mood as well as certain cognitive functions in dementia (see review by Cotelli et al., 2012). Reminiscence therapy and life review are related but distinct interventions (e.g. Haight and Burnside, 1993). Simple reminiscence therapy employs memories from participants' past (e.g. details about where they grew up, events such as weddings) to benefit mental health. Life review involves a more comprehensive process of bringing together experiences from a person's past into a coherent whole that is personally meaningful (e.g. Butler, 1963), consistent with Erikson's (1950) description of ego integrity in later life, where one has adapted psychologically to the positive and negative aspects of one's life, as opposed to despair, where a fear of death accompanies one's inability to fully accept one's life.
A well-powered study of reminiscence therapy did not find an overall effect of group reminiscence therapy in people with dementia, although more frequent attendance at the sessions was associated with improvement in AM (Woods et al., 2016). Simple reminiscence therapy has been found to increase retrieval of autobiographical events in people with cognitive impairment (Lopes et al., 2016), and in a study with clearer differentiation between mild cognitive impairment and dementia, reminiscence therapy increased both episodic and semantic $\mathrm{AM}$ in people with amnestic mild cognitive impairment (aMCI) and episodic AM in people with AD (Melendez et al., 2015). In a study of non-demented older adults, neither autobiographical writing nor oral reminiscence improved $\mathrm{AM}$; more positive memories were recalled following the intervention at an 8-week and 34-week follow-up, although this was also observed in the control group (De Medeiros et al., 2011). A reminiscence program specifically targeting semantic and episodic memory (REMau) increased episodic and semantic AM in people with mild-moderate $\mathrm{AD}$, whereas a control condition involving 
training of non-autobiographical forms of memory did not (Lalanne et al., 2015). A brief, simple intervention requiring participants to complete statements describing themselves was associated with heightened reliving, context recall and memory specificity in people with probable AD (El Haj and Antoine, 2017).

Morgan (2000) studied life review in people with dementia and its effects on AM. Compared to a no-treatment control group, participants in the life review group performed better at the personal semantic scale of the interview (indicating better recall of facts from earlier in their lives). However, those in the life review group did not perform better at an episodic AM measure, although the life review group had a higher performance at baseline. Later research has found that life review with co-creation of a life story book was associated with improved episodic and semantic AM (Subramaniam et al., 2014). Life review has also been found to increase specific memories in older adults with depression but no signs of dementia (Gonçalves et al., 2009; Serrano et al., 2004). Serrano et al. (2004) found a correlation between the number of memories produced in the intervention and the increase in specific memories assessed before and after the intervention. The potential impact of depression on AM (Lemogne et al., 2006; Ricarte et al., 2011; Serrano et al., 2007), such as reduced specificity of episodic AM, should be borne in mind in this context. In assessing the impact of reminiscence therapy or life review, care should be taken to ascertain whether a memory recalled for evaluation has recently been recalled during a reminiscence therapy session. If a memory has recently been reported, then a subsequent report is likely to access the memory of a recent report or rehearsal thereof, as well as the remote memory of the event itself.

Music has been associated with improved AM performance in people with dementia (Foster and Valentine, 2001; Irish et al., 2006), with sad music in particular being associated with improved remote AM (García et al., 2012). Interestingly, this effect was seen with classical music; other research indicating a positive effect allowed participants to choose their favourite music (El Haj et al., 2013), which may be more evocative of an earlier period in their life. It is also interesting that a positive effect could be seen with an intervention involving minimal time investment. In addition to listening to music, singing has also been found to improve AM (Särkämö et al., 2014). Table 1 summarises the characteristics of studies examining AM and psychological interventions for older adults (these articles were identified via PubMed, ScienceDirect and PSYCHinfo using the search terms "autobiographical memory" AND "reminiscence" OR "life review" OR "music therapy" OR "mindfulness" OR "meditation" AND "dementia" OR "depression" OR "older" OR "elderly").

\subsection{Mechanisms}

Executive function (i.e. "general cognitive processes that support strategic organisation and control other processes important to complex, goal-oriented tasks" Buckner, 2004, p. 197) is likely to play a key role in $\mathrm{AM}$ and how it is affected by ageing, dementia, and interventions that can improve cognition (e.g. Benjamin et al., 2015). An executive account of AM dysfunction highlights the role of higher-order processes such as the organisation and memory search strategies of AM, as opposed to loss of "stored" AM (e.g. El Haj et al., 2015). A number of factors can lead to decline in executive function in ageing, including reduced dorsolateral prefrontal cortex function (MacPherson et al., 2002) and striatal dopamine levels (e.g. Bäckman et al., 2000; Volkow et al., 1998). Where executive function performance is relatively preserved in ageing, this may be due to a compensatory mechanism such as a reduction in asymmetry in prefrontal activation posited by the HAROLD model (Cabeza, 2002; see section 2.1). If this is the case, a key empirical question is whether psychological interventions (including those that target executive function) may facilitate this compensation.

The relevance of different forms of executive function to AM will depend on whether AM is episodic or semantic, as well as whether one is considering successful retrieval of true AM versus avoiding retrieval of false AM. Inhibitory processes, particularly the ability to inhibit irrelevant stimuli when recalling AM, are likely to reduce the incidence of false AM; such false AM may be due to frontal lobe dysfunction in dementia (e.g. Budson et al., 2002). Healthy older adults have been found to be more susceptible to erroneously incorporating elements of one memory into another memory (conjunction errors) in AM, which may be related to dysfunctional inhibitory capacity (Devitt et al., 2016). Executive function has been linked not only to avoiding false AM, but also to the episodic richness of AM. In older adults, the decline in richness of episodic AM has been associated with a decline in executive functions (set shifting and inhibition) (Martinelli et al., 2013b). Reduced working memory executive processes in ageing were associated with worsened overgeneralised AM (Ros et al., 2009), which is suggestive of reduced episodic richness.

Dementia is associated with impairment in executive function, although the level and form of impairment may depend upon diagnosis and prognosis. Within people with behavioural variant frontotemporal dementia, those with fast progression had impairment on a number of tests of executive function assessing working memory, inhibitory control, letter fluency and set shifting. In contrast, non-progressors were relatively unimpaired (Hornberger et al., 2008). People with mild AD had impaired inhibitory capacity for AM, compared to relatively preserved inhibitory capacity in healthy older adults (El Haj et al., 2011). Research contrasting frontotemporal dementia with "typical" AD (associated with memory, language and perceptuospatial impairment) found that the former was associated with problems in inhibition and set-shifting, as well as sustained attention, whereas AD impairment appeared to be more linked to working memory capacity; further, they distinguished the typical $\mathrm{AD}$ group from an amnestic $\mathrm{AD}$ group, who performed better at tests of executive function (Stopford et al., 2012). However, other research has found more pervasive executive dysfunction in people with AD (Collette et al., 1999).

There is existing evidence that executive function is associated with $\mathrm{AM}$ in dementia, and that interventions that target $\mathrm{AM}$ can improve executive function. In people with $\mathrm{AD}$, verbal fluency has been associated with retrieval of episodic AM, while divided attention has been implicated in retrieval of semantic AM (Greene et al., 1995). Mindfulness-based cognitive therapy that heightened AM in adults (the mean age of this sample was mid-50's) also improved the capacity to inhibit prepotent responses (as well as cognitive flexibility) (Heeren et al., 2009) and mindfulness-based stress reduction (MBSR) enhanced setshifting in older adults (Moynihan et al., 2013). Mindfulness training has consistently been linked with the anterior cingulate cortex, which is involved in executive function (see review by Tang et al., 2015). There is also separate evidence that music can enhance category fluency in healthy older adults and people with AD (Vivaldi's "Four Seasons": Thompson et al., 2005), and music was also associated with enhanced verbal fluency and a reduction in the use of empty words (e.g. "sort of", "you know"), (El Haj et al., 2013). Studies in people with dementia have not found a significant effect of reminiscence therapy on the MMSE, a global measure of cognition (Akanuma et al., 2011; Goldwasser et al., 1987; Lai et al., 2004), suggesting a more specific cognitive effect. Although music may enhance executive functioning, it has also been observed that music that is familiar from a person's past can trigger faster AM retrieval that engages less executive processing; suggesting that familiar music leads to more automatic AM that bypasses the executive processes that would be recruited for more effortful AM retrieval (El Haj et al., 2012).

Mood and stress may also mediate the impact of psychological interventions on episodic memory. Stressors such as daily hassles, as well as stressful life events such as bereavement or having to care for a family member with dementia (e.g. Allen et al., 2017), may exacerbate negative effects of ageing on cognition (Aggarwal et al., 2014; Prenderville et al., 2015). This effect may be particularly pronounced in the case of episodic memory tasks requiring greater executive resources 
in particular (VonDras et al., 2005). However, longitudinal research has found that recent stressful life events worsened memory decline only in adults with cognitive impairment, not in healthy aged adults (Peavy et al., 2009). A music intervention has been shown to reduce anxiety as well as improving AM (Irish et al., 2006), suggesting that the alleviation of anxiety may play a role in enhancing AM. There is evidence that reminiscence therapy can improve mood and reduce depression in older adults (Wang, 2005) as well as reducing anxiety (Scates et al., 1986). Similarly, mindfulness-based stress reduction can reduce depression as well as anxiety in older adults (Young and Baime, 2010). If interventions improve management of chronic stress or anxiety, and improve mood/reduce depression, this could represent a means to improve AM, and possibly executive function as well. Furthermore, deficits in AM may themselves trigger depression and lower mood state, suggesting that interventions that improve AM may themselves help to ameliorate depression (Dalgleish and Werner-Seidler, 2014; Schneider and Brassen, 2016).

As well as being a mediator of interventions that affect AM, improved mood and reduced stress could be an outcome of improved executive function. If executive function is improved, then a by-product may be increased self-regulation of mood and emotion (see review by Hofmann et al., 2012). Conversely, there is some evidence that stress can reduce executive function in healthy populations and reduce activity in the executive regions (dorsolateral prefrontal cortex) and default mode network (Qin et al., 2009). As such, an intervention that reduces stress could effectively improve executive function. We therefore suggest that executive function has a bidirectional relationship with mood and stress.

In addition to "normal" life stress, it is worth considering that stressrelated disorders have been associated with reduced specificity in AM, including posttraumatic stress disorder (McNally et al., 1995), acute stress disorder (Harvey et al., 1998) and major depression (see Section 3.1). Major depression occurs frequently in people with dementia (e.g. Migliorelli et al., 1995; see review by Cipriani et al., 2015). Furthermore, there is some evidence that people with mild cognitive impairment are at greater risk of developing dementia of Alzheimer type over a three-year follow-up if they also suffer from depression (Modrego and Ferrández, 2004), and although the evidence on later-life depression in general and dementia is conflicting, there appears to be a clear association between early-life depression and dementia in later life (see review by Byers and Yaffe, 2011). However, prevalence and severity of depression may vary depending upon dementia diagnosis, with some evidence that depression is more prevalent and severe in vascular dementia compared to AD (Ballard et al., 1996).

An underlying factor linking depression as a stress-related disorder to the emergence of dementia in ageing is hypersecretion of the hormone cortisol, which is released in response to stress (Lupien et al., 1999). This in turn can lead to immune system effects which may represent a common pathophysiology of both depression and dementia (e.g. Leonard and Myint, 2006). As highlighted above, there is evidence that life review can improve AM in people with depression, and these studies also indicated a reduction in depressive symptoms (Gonçalves et al., 2009; Serrano et al., 2004), suggesting that alleviation of stressrelated disorder by life review is accompanied by improved AM.

\section{Discussion}

\subsection{Significance/model of mechanisms}

We outline a model of factors mediating the effects of interventions on AM in Fig. 2. This model is not intended to be exhaustive, but rather to highlight key cognitive and affective factors mediating the positive effects of reminiscence, music and mindfulness interventions on AM. We also suggest that reminiscence therapy and music listening should improve AM not only via affective factors and executive function, but also via direct effects on AM, as autobiographical material is dealt with directly in these approaches. (In contrast, mindfulness-based interventions tend to focus on the current moment.)

According to this model, we predict that interventions that successfully enhance executive function, improve mood and reduce stress and anxiety will enhance AM. This mediation model aligns with Multiple Trace Theory in implicating both neocortical and subcortical regions in AM and its rehabilitation. However, this model extends the dual role of neocortical and subcortical regions beyond the storage and retrieval of $\mathrm{AM}$ itself, as both are involved in factors mediating therapeutic impact on AM; both neocortical (e.g. prefrontal cortices) executive mechanisms and subcortical (e.g. amygdala, hippocampus) stress and anxiety mechanisms will influence AM. These mediating effects should be observed both in non-pathological age-related cognitive decline as well as in dementia, although in individuals where executive function and AM are very well preserved, it may not be possible to alter these outcomes due to ceiling effects.

\subsection{Future directions for research}

More longitudinal research will give a deeper understanding of how $\mathrm{AM}$ changes with the ageing process. Full consolidation for AM can take years to decades to occur. The consolidation of important AM may thus span the transition from healthy ageing to mild cognitive impairment to dementia. Furthermore, the contents of AM may be altered by different motivational factors as time goes on, and rehearsal of AM in life review/reminiscence therapy will impact upon key AM that is used in the therapeutic process. Changes in brain network connectivity and changes in AM performance tracked over multiple periods of time can allow for the cause that precedes the effect to be identified.

Although investigation of moderating factors has been limited in previous research (perhaps due to restricted sample size), these factors should also be considered. Most of the intervention research has involved predominantly female participants, although the largest study had a good level of gender balance (Woods et al., 2016). Nonetheless, it should be noted that gender may moderate AM content in older adults, with females giving a higher level of episodic detail (Pillemer et al., 2003). As much of the theory and research in this area has examined the distinction between episodic and semantic AM, it will be important to include more males in future research to examine the robustness of effects specific to episodic or semantic AM. Among the many other potential moderating factors to consider, level of education and subsequent learning and occupation are highly salient, as such factors can bolster cognitive reserve against impairment in ageing (e.g. Chapko et al., in press; Opdebeeck et al., 2016; Whalley et al., 2004). Another interesting factor to consider is migration to a different country over the course of one's life, which may be further complicated by the language in which retrieval is verbalised (Schrauf and Rubin, 1998, 2001).

Understanding of AM can be enhanced not only by studying clinical conditions associated with AM impairment, but also by the study of hyperthymestic syndrome or highly superior autobiographical memory (HSAM; see Parker et al., 2006). Initial evidence has found neuroanatomical alterations in adults with HSAM, despite average performance on other aspects of memory compared to age-and sex-matched controls (LePort et al., 2012). For adults with HSAM, LePort et al. (2012) observed higher grey matter concentrations in the vicinity of the right anterior putamen, caudate and posterior pallidum, and lower grey matter concentration bilaterally for the anterior pole and adjacent middle temporal gyrus and at the banks of the intraparietal sulcus. They also observed lower white matter concentrations, for the right posterior pallidum and lingual gyrus, and bilaterally for the anterior limb of the internal capsule, anterior pole and adjacent middle temporal gyrus. However, it is difficult to draw conclusions on ageing within this condition, as this study employed a small sample with a wide age range. Observed differences in brain regions may likely be due to high levels of practice in AM rehearsal and retrieval; for example, in the case reported by Parker et al. (2006), the participant with HSAM had kept diaries 


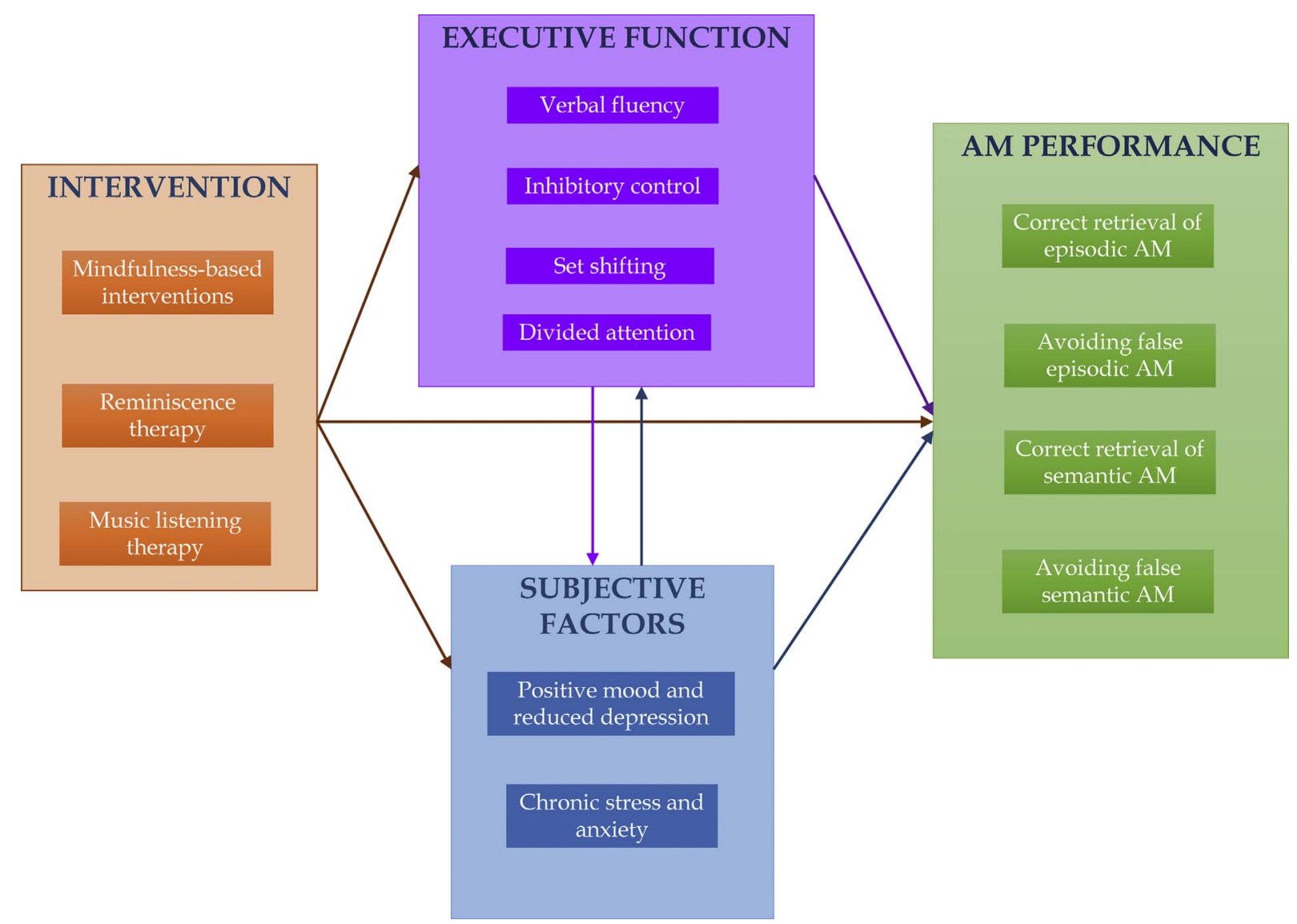

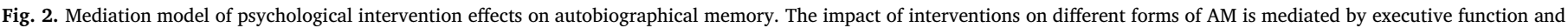
subjective factors.

between the ages of 10 and 34. Remarkably, people with HSAM may be as vulnerable to false AM as control participants (Patihis et al., 2013), perhaps due to high levels of rehearsal being applied to false as well as true AM. Follow-up with people with HSAM could inform of how networks of brain regions operate under these conditions, and whether ageing is associated with a differential level of decline in HSAM.

Previous theoretical work in memory processes has taken a neurophenomenological approach, i.e. a combination of first-person, subjective report with neurocognitive results (e.g. the model proposed by Dalla Barba and La Corte, 2015). The neuroscientific study of AM is an excellent field for neurophenomenological research that combines the complex data from brain imaging technologies such as fMRI with the rich, first-person data generated during reports of AM. Existing research has used experience sampling in conjunction with fMRI to study mind wandering (Christoff et al., 2009; McCormick et al., in press); a similar method would be of interest in AM reporting. It has been argued that a neurophenomenological approach is an enactive and embodied approach to cognition (e.g. Robbins, 2013; Varela, 1996). As AM refers to experiences that have usually been generated in more ecologically complex conditions than the laboratory and that have involved a more active interaction between the person and their environment, AM represents a natural opportunity to study enactive and embodied cognition. However, the complexity of such an endeavour should not be underestimated; for example, if reporting of an AM occurs under controlled laboratory conditions (e.g. when undergoing an fMRI scan), then it is likely the encoding of AM that is more enactive than retrieval, unless there is scope for the participant to seek out artefacts to aid in AM retrieval.

\section{Conclusions}

Although further research in this area is required, AM in healthy ageing and dementia offers some support for compensatory models of the ageing brain such as HAROLD and CRUNCH. Furthermore, the temporal gradient of AM loss with age, and particularly in cases of dementia, offers insight into more specific neural theories of AM, such as Cortical Reallocation and Multiple Trace Theory. However, the impact of dementia on AM appears to depend upon specific diagnosis. Life review appears to increase semantic AM in people with dementia, and episodic AM in people with major depression, while an intervention targeting both semantic and episodic AM (REMau) can improve both of these aspects of $\mathrm{AM}$, and adherence to reminiscence-based therapies appears to be important for effects on AM performance. Music can also enhance AM, with music from a person's youth perhaps exercising a more direct effect on AM. Executive function appears to be a key mediator of the effects of psychological therapies on AM, but further, well-designed research is required in this area.

Future research employing more longitudinal and neurophenomenological approaches and examining moderating factors such as gender and level of education will deepen our understanding of people's memories of their past, in both healthy ageing and dementia. Memories of one's past are of personal significance to older people, as well as to carers of people with dementia, and memories rich in episodic detail can be of benefit to quality of life. We hope that the model we propose here can help to refine hypotheses in research concerning AM in ageing populations and psychological interventions to improve memory of the past, including personal history as well as memories of broader historical events. 


\section{Acknowledgements}

The authors are supported by a New Horizons grant from the Irish Research Council (REF: REPRO BU 2050158). Conflicts of interest: none.

\section{References}

Addis, D.R., McIntosh, A.R., Moscovitch, M., Crawley, A.P., McAndrews, M.P., 2004. Characterizing spatial and temporal features of autobiographical memory retrieval networks: a partial least squares approach. Neuroimage 23 (4), 1460-1471.

Aggarwal, N.T., Wilson, R.S., Beck, T.L., Rajan, K.B., de Leon, C.F.M., Evans, D.A., Everson-Rose, S.A., 2014. Perceived stress and change in cognitive function among adults aged 65 and older. Psychosom. Med. 76 (1), 80-85.

Akanuma, K., Meguro, K., Meguro, M., Sasaki, E., Chiba, K., Ishii, H., Tanaka, N., 2011. Improved social interaction and increased anterior cingulate metabolism after group reminiscence with reality orientation approach for vascular dementia. Psychiatry Res. Neuroimaging 192 (3), 183-187.

Allen, A.P., Curran, E.A., Duggan, Á., Cryan, J.F., Chorcoráin, A.N., Dinan, T.G., Molloy, D.W., Kearney, P.M., Clarke, G., 2017. A systematic review of the psychobiological burden of informal caregiving for patients with dementia: focus on cognitive and biological markers of chronic stress. Neurosci. Biobehav. Rev. 73, 123-164.

Alvarez, P., Squire, L.R., 1994. Memory consolidation and the medial temporal lobe: a simple network model. Proc. Natl. Acad. Sci. U. S. A. 91 (15), 7041-7045.

Bäckman, L., Ginovart, N., Dixon, R.A., Wahlin, T.B.R., Wahlin, ̊., Halldin, C., Farde, L., 2000. Age-related cognitive deficits mediated by changes in the striatal dopamine system. Am. J. Psychiatry 157 (4), 635-637.

Bahar-Fuchs, A., Clare, L., Woods, B., 2013. Cognitive training and cognitive rehabilitation for mild to moderate Alzheimer's disease and vascular dementia. Cochrane Database Syst. Rev 6.

Ballard, C., Bannister, C., Solis, M., Oyebode, F., Wilcock, G., 1996. The prevalence, associations and symptoms of depression amongst dementia sufferers. J. Affect. Disord. 36 (3), 135-144.

Barry, D.N., Coogan, A.N., Commins, S., 2016. The time course of systems consolidation of spatial memory from recent to remote retention A comparison of the Immediate Early Genes Zif268, c-Fos and Arc. Neurobiol. Learn. Mem. 128, 46-55.

Benjamin, M.J., Cifelli, A., Garrard, P., Caine, D., Jones, F.W., 2015. The role of working memory and verbal fluency in autobiographical memory in early Alzheimer's disease and matched controls. Neuropsychologia 78, 115-121.

Bonnici, H.M., Maguire, E.A., Two years later-revisiting autobiographical memory representations in vmPFC and hippocampus. Neuropsychologia. (in press) https://dx. doi.org/10.1016/j.neuropsychologia.2017.05.014.

Bonnici, H.M., Chadwick, M.J., Lutti, A., Hassabis, D., Weiskopf, N., Maguire, E.A., 2012. Detecting representations of recent and remote autobiographical memories in vmPFC and hippocampus. J. Neurosci. 32 (47), 16982-16991.

Braak, H., Braak, E., 1991. Neuropathological stageing of Alzheimer-related changes Acta Neuropathol. 82 (4), 239-259.

Buckner, R.L., 2004. Memory and executive function in aging and AD: multiple factors that cause decline and reserve factors that compensate. Neuron 44 (1), 195-208.

Budson, A.E., Sullivan, A.L., Mayer, E., Daffner, K.R., Black, P.M., Schacter, D.L., 2002. Suppression of false recognition in Alzheimer's disease and in patients with frontal lobe lesions. Brain 125 (12), 2750-2765.

Butler, R.N., 1963. The life review: an interpretation of reminiscence in the aged. Psychiatry 26 (1), 65-76.

Byers, A.L., Yaffe, K., 2011. Depression and risk of developing dementia. Nat. Rev. Neurol. 7 (6), 323-331.

Cabeza, R., 2002. Hemispheric asymmetry reduction in older adults: the HAROLD model. Psychol. Aging 17 (1), 85-100.

Caddell, L.S., Clare, L., 2010. The impact of dementia on self and identity: a systematic review. Clin. Psychol. Rev. 30 (1), 113-126.

Chapko, D., McCormack, R., Black, C., Staff, R., Murray, A., Life-course determinants of cognitive reserve (CR) in cognitive aging and dementia-a systematic literature review. Aging Ment. Health. (in press) https://dx.doi.org/10.1080/13607863.2017. 1348471 .

Christoff, K., Gordon, A.M., Smallwood, J., Smith, R., Schooler, J.W., 2009. Experience sampling during fMRI reveals default network and executive system contributions to mind wandering. Proc. Natl. Acad. Sci. U. S. A. 106 (21), 8719-8724.

Cipriani, G., Lucetti, C., Carlesi, C., Danti, S., Nuti, A., 2015. Depression and dementia. A review. Eur. Geriatr. Med. 6 (5), 479-486.

Clayton, N.S., Dickinson, A., 1998. Episodic-like memory during cache recovery by scrub jays. Nat 395 (6699), 272-274.

Collette, F., Van der Linden, M., Salmon, E., 1999. Executive dysfunction in Alzheimer's disease. Cortex 35 (1), 57-72.

Conway, M.A., Pleydell-Pearce, C.W., 2000. The construction of autobiographical memories in the self-memory system. Psychol. Rev. 107 (2), 261-288.

Conway, M.A., Tacchi, P.C., 1996. Motivated confabulation. Neurocase 2 (4), 325-339.

Cooper, J.M., Shanks, M.F., Venneri, A., 2006. Provoked confabulations in Alzheimer's disease. Neuropsychologia 44 (10), 1697-1707.

Cotelli, M., Manenti, R., Zanetti, O., 2012. Reminiscence therapy in dementia: a review. Maturitas 72 (3), 203-205.

Dalgleish, T., Werner-Seidler, A., 2014. Disruptions in autobiographical memory processing in depression and the emergence of memory therapeutics. Trends Cogn. Sci. 18 (11), 596-604.
Dall'Ora, P., Della Sala, S., Spinnler, H., 1989. Autobiographical memory. Its impairment in amnesic syndromes. Cortex 25 (2), 197-217.

Dalla Barba, G., La Corte, V., 2015. A neurophenomenological model for the role of the hippocampus in temporal consciousness. Evidence from confabulation. Front. Behav. Neurosci. 9, 218.

Davis, K.E., Eacott, M.J., Easton, A., Gigg, J., 2013. Episodic-like memory is sensitive to both Alzheimer's-like pathological accumulation and normal ageing processes in mice. Behav. Brain Res. 254, 73-82.

De Medeiros, K., Mosby, A., Hanley, K.B., Pedraza, M.S., Brandt, J., 2011. A randomized clinical trial of a writing workshop intervention to improve autobiographical memory and well-being in older adults. Int. J. Geriatr. Psychiatry 26 (8), 803-811.

Devitt, A.L., Tippett, L., Schacter, D.L., Addis, D.R., 2016. Autobiographical memory conjunction errors in younger and older adults: evidence for a role of inhibitory ability. Psychol. Aging 31 (8), 927-942.

Dritschel, B.H., Williams, J.M., Baddley, A.D., Nimmo-Smith, I., 1992. Autobiographical fluency: A method for the study of personal memory. Mem. Cognit. 20, 133-140.

Duncan, J., Owen, A.M., 2000. Common regions of the human frontal lobe recruited by diverse cognitive demands. Trends Neurosci. 23 (10), 475-483.

Duval, C., Desgranges, B., de La Sayette, V., Belliard, S., Eustache, F., Piolino, P., 2012. What happens to personal identity when semantic knowledge degrades? A study of the self and autobiographical memory in semantic dementia. Neuropsychologia 50 (2), 254-265.

Eacott, M.J., Norman, G., 2004. Integrated memory for object, place, and context in rats: a possible model of episodic-like memory? J. Neurosci. 24 (8), 1948-1953.

El Haj, M., Antoine, P., 2017. Describe yourself to improve your autobiographical memory: a study in Alzheimer's disease. Cortex 88, 165-172.

El Haj, M., Postal, V., Le Gall, D., Allain, P., 2011. Directed forgetting of autobiographical memory in mild Alzheimer's disease. Memory 19 (8), 993-1003.

El Haj, M., Fasotti, L., Allain, P., 2012. The involuntary nature of music-evoked autobiographical memories in Alzheimer's disease. Conscious. Cogn. 21 (1), 238-246.

El Haj, M., Clément, S., Fasotti, L., Allain, P., 2013. Effects of music on autobiographical verbal narration in Alzheimer's disease. J. Neurolinguistics 26 (6), 691-700.

El Haj, M., Antoine, P., Nandrino, J.L., Kapogiannis, D., 2015. Autobiographical memory decline in Alzheimer's disease, a theoretical and clinical overview. Ageing Res. Rev. 23, 183-192.

Erikson, E., 1950. Childhood and Society. Norton, New York.

Fitzgerald, J.M., Broadbridge, C.L., 2012. Theory and research in autobiographical memory: a life-span developmental perspective. In: Bernsten, D., Rubin, D.C. (Eds.), Understanding Autobiographical Memory. Cambridge University Press, Cambridge, UK, pp. 246-266.

Foster, N.A., Valentine, E.R., 2001. The effect of auditory stimulation on autobiographical recall in dementia. Exp. Aging Res. 27 (3), 215-228.

Frankland, P.W., Bontempi, B., 2005. The organization of recent and remote memories. Nat. Rev. Neurosci. 6 (2), 119-130.

García, J.J.M., Iodice, R., Carro, J., Sánchez, J.A., Palmero, F., Mateos, A.M., 2012 Improvement of autobiographic memory recovery by means of sad music in Alzheimer's disease type dementia. Aging Clin. Exp. Res. 24 (3), 227-232.

Goldwasser, A.N., Auerbach, S.M., Harkins, S.W., 1987. Cognitive, affective, and behavioral effects of reminiscence group therapy on demented elderly. Int. J. Aging Hum. Dev. 25 (3), 209-222.

Gonçalves, D.C., Albuquerque, P.B., Paúl, C., 2009. Life review with older women: an intervention to reduce depression and improve autobiographical memory. Aging Clin. Exp. Res. 21 (4/5), 369-371.

Good, M.A., Hale, G., Staal, V., 2007. Impaired episodic-like object memory in adult APPswe transgenic mice. Behav. Neurosci. 121 (2), 443-448.

Graham, K.S., Hodges, J.R., 1997. Differentiating the roles of the hippocampus complex and the neocortex in long-term memory storage: evidence from the study of semantic dementia and Alzheimer's disease. Neuropsychology 11 (1), 77-89.

Greenberg, D.L., Rubin, D.C., 2003. The neuropsychology of autobiographical memory. Cortex 39 (4), 687-728.

Greene, J.D., Hodges, J.R., Baddeley, A.D., 1995. Autobiographical memory and executive function in early dementia of Alzheimer type. Neuropsychologia 33 (12), 1647-1670.

Haight, B.K., Burnside, I., 1993. Reminiscence and life review: explaining the differences. Arch. Psychiatr. Nurs. 7 (2), 91-98.

Harvey, A.G., Bryant, R.A., Dang, S.T., 1998. Autobiographical memory in acute stress disorder. J. Consult. Clin. Psychol. 66 (3), 500-506.

Hebscher, M., Levine, B., Gilboa, A., The precuneus and hippocampus contribute to individual differences in the unfolding of spatial representations during episodic autobiographical memory. Neuropsychologia. (in press) https://dx.doi.org/10.1016/j. neuropsychologia.2017.03.029.

Heeren, A., Van Broeck, N., Philippot, P., 2009. The effects of mindfulness on executive processes and autobiographical memory specificity. Behav. Res. Ther. 47 (5), 403-409.

Hofmann, W., Schmeichel, B.J., Baddeley, A.D., 2012. Executive functions and self-regulation. Trends Cogn. Sci. 16 (3), 174-180.

Hornberger, M., Piguet, O., Kipps, C., Hodges, J.R., 2008. Executive function in progressive and nonprogressive behavioral variant frontotemporal dementia. Neurology 71 (19), 1481-1488.

Irish, M., Cunningham, C.J., Walsh, J.B., Coakley, D., Lawlor, B.A., Robertson, I.H., Coen, R.F., 2006. Investigating the enhancing effect of music on autobiographical memory in mild Alzheimer's disease. Dement. Geriatr. Cogn. Disord 22 (1), 108-120.

Irish, M., Lawlor, B.A., O'Mara, S.M., Coen, R.F., 2008. Assessment of behavioural markers of autonoetic consciousness during episodic autobiographical memory retrieval: a preliminary analysis. Behav. Neurol. 19 (1-2), 3-6.

Irish, M., Hornberger, M., Lah, S., Miller, L., Pengas, G., Nestor, P.J., Hodges, J.R., Piguet, 
O., 2011. Profiles of recent autobiographical memory retrieval in semantic dementia, behavioural-variant frontotemporal dementia, and Alzheimer's disease. Neuropsychologia 49 (9), 2694-2702.

Irish, M., Landin-Romero, R., Mothakunnel, A., Ramanan, S., Hsieh, S., Hodges, J.R., Piguet, O., Evolution of autobiographical memory impairments in Alzheimer's disease and frontotemporal dementia?A longitudinal neuroimaging study. Neuropsychologia. (in press) https://dx.doi.org/10.1016/j.neuropsychologia.2017.03.014.

Ivanoiu, A., Cooper, J.M., Shanks, M.F., Venneri, A., 2006. Patterns of impairment in autobiographical memory in the degenerative dementias constrain models of memory. Neuropsychologia 44 (10), 1936-1955.

Kelly, M.E., Loughrey, D., Lawlor, B.A., Robertson, I.H., Walsh, C., Brennan, S., 2014. The impact of cognitive training and mental stimulation on cognitive and everyday functioning of healthy older adults: a systematic review and meta-analysis. Ageing Res. Rev. 15, 28-43.

Kitamura, T., Ogawa, S.K., Roy, D.S., Okuyama, T., Morrissey, M.D., Smith, L.M., Redondo, R.L., Tonegawa, S., 2017. Engrams and circuits crucial for systems consolidation of a memory. Sci 356 (6333), 73-78.

Kopelman, M.D., Wilson, B.A., Baddeley, A.D., 1989. The autobiographical memory interview: a new assessment of autobiographical and personal semantic memory in amnesic patients. J. Clin. Exp. Neuropsychol. 11 (5), 724-744.

Kumfor, F., Teo, D., Miller, L., Lah, S., Mioshi, E., Hodges, J.R., Piguet, O., Irish, M., 2016. Examining the relationship between autobiographical memory impairment and carer burden in dementia syndromes. J. Alzheimers Dis. 51 (1), 237-248.

LaBar, K.S., Cabeza, R., 2006. Cognitive neuroscience of emotional memory. Nat. Rev. Neurosci. 7 (1), 54-64.

Lai, C.K., Chi, I., Kayser-Jones, J., 2004. A randomized controlled trial of a specific reminiscence approach to promote the well-being of nursing home residents with dementia. Int. Psychogeriatr. 16 (1), 33-49.

Lalanne, J., Gallarda, T., Piolino, P., 2015. The Castle of Remembrance: new insights from a cognitive training programme for autobiographical memory in Alzheimer's disease. Neuropsychol. Rehabil. 25 (2), 254-282.

Langston, R.F., Wood, E.R., 2010. Associative recognition and the hippocampus: differential effects of hippocampal lesions on object-place, object-context and object-placecontext memory. Hippocampus 20 (10), 1139-1153.

LePort, A.K., Mattfeld, A.T., Dickinson-Anson, H., Fallon, J.H., Stark, C.E., Kruggel, F., Cahill, L., McGaugh, J.L., 2012. Behavioral and neuroanatomical investigation of highly superior autobiographical memory (HSAM). Neurobiol. Learn. Mem. 98 (1), 78-92.

Lemogne, C., Piolino, P., Friszer, S., Claret, A., Girault, N., Jouvent, R., Allilaire, J.F., Fossati, P., 2006. Episodic autobiographical memory in depression: specificity, autonoetic consciousness, and self-perspective. Conscious. Cogn. 15 (2), 258-268.

Leonard, B.E., Myint, A., 2006. Changes in the immune system in depression and dementia: causal or coincidental effects? Dialogues Clin. Neurosci. 8 (2), 163.

Levine, B., Svoboda, E., Hay, J.F., Winocur, G., Moscovitch, M., 2002. Aging and autobiographical memory: dissociating episodic from semantic retrieval. Psychol. Aging 17 (4), 677-689.

Leyhe, T., Müller, S., Milian, M., Eschweiler, G.W., Saur, R., 2009. Impairment of episodic and semantic autobiographical memory in patients with mild cognitive impairment and early Alzheimer's disease. Neuropsychologia 47 (12), 2464-2469.

Lopes, T.S., Afonso, R.M.L.B.M., Ribeiro, Ó.M., 2016. A quasi-experimental study of a reminiscence program focused on autobiographical memory in institutionalized older adults with cognitive impairment. Arch. Gerontol. Geriatr. 66, 183-192.

Lupien, S.J., Nair, N.P.V., Briere, S., Maheu, F., Tu, M.T., Lemay, M., McEwen, B.S., Meaney, M.J., 1999. Increased cortisol levels and impaired cognition in human aging: implication for depression and dementia in later life. Rev. Neurosci. 10 (2), 117-140.

MacPherson, S.E., Phillips, L.H., Della Sala, S., 2002. Age, executive function and social decision making: a dorsolateral prefrontal theory of cognitive aging. Psychol. Aging 17 (4), 598-609.

Maguire, E.A., Frith, C.D., 2003. Aging affects the engagement of the hippocampus during autobiographical memory retrieval. Brain 126 (7), 1511-1523.

Maguire, E.A., Mummery, C.J., 1999. Differential modulation of a common memory retrieval network revealed by positron emission tomography. Hippocampus 9 (1), 54-61.

Martinelli, P., Sperduti, M., Devauchelle, A.D., Kalenzaga, S., Gallarda, T., Lion, S., Delhommeau, M., Anssens, A., Amado, I., Meder, J.F., Krebs, M.O., 2013a. Age-related changes in the functional network underlying specific and general autobiographical memory retrieval: a pivotal role for the anterior cingulate cortex. PLoS One 8 (12), e82385.

Martinelli, P., Anssens, A., Sperduti, M., Piolino, P., 2013b. The influence of normal aging and Alzheimer's disease in autobiographical memory highly related to the self. Neuropsychology 27 (1), 69-78.

Mazzoni, G., Memon, A., 2003. Imagination can create false autobiographical memories. Psychol. Sci. 14 (2), 186-188.

McCormick, C., Rosenthal, C.R., Miller, T.D., Maguire, E., Mind-wandering in people with hippocampal amnesia. bioRxiv. (159681) (in press).

McKinnon, M.C., Nica, E.I., Sengdy, P., Kovacevic, N., Moscovitch, M., Freedman, M., Miller, B.L., Black, S.E., Levine, B., 2008. Autobiographical memory and patterns of brain atrophy in fronto-temporal lobar degeneration. J. Cogn. Neurosci. 20 (10), 1839-1853.

McNally, R.J., Lasko, N.B., Macklin, M.L., Pitman, R.K., 1995. Autobiographical memory disturbance in combat-related posttraumatic stress disorder. Behav. Res. Ther. 33 (6), 619-630.

Melendez, J.C., Torres, M., Redondo, R., Mayordomo, T., Sales, A., 2015. Effectiveness of follow-up reminiscence therapy on autobiographical memory in pathological ageing. Int. J. Psychol. 52 (4), 283-290.

Migliorelli, R., Teson, A., Sabe, L., Petracchi, M., 1995. Prevalence and correlates of dysthymia and major depression among patients with Alzheimer's disease. Am. J. Psychiatry 152 (1), 37-44.

Modrego, P.J., Ferrández, J., 2004. Depression in patients with mild cognitive impairment increases the risk of developing dementia of Alzheimer type: a prospective cohort study. Arch. Neurol. 61 (8), 1290-1293.

Morgan, S., 2000. The Impact of a Structured Life Review Process on People with Memory Problems Living in Care Homes. Prifysgol Bangor University, Doctoral dissertation.

Moynihan, J.A., Chapman, B.P., Klorman, R., Krasner, M.S., Duberstein, P.R., Brown,

K.W., Talbot, N.L., 2013. Mindfulness-based stress reduction for older adults: effects on executive function, frontal alpha asymmetry and immune function. Neuropsychobiology 68 (1), 34-43.

Murphy, K.J., Troyer, A.K., Levine, B., Moscovitch, M., 2008. Episodic, but not semantic, autobiographical memory is reduced in amnestic mild cognitive impairment. Neuropsychologia 46 (13), 3116-3123.

Nadel, L., Moscovitch, M., 1997. Memory consolidation, retrograde amnesia and the hippocampal complex. Curr. Opin. Neurobiol. 7 (2), 217-227.

Nyberg, L., Tulving, E., 1996. Classifying human long-term memory: evidence from converging dissociations. Eur. J. Cogn. Psychol. 8 (2), 163-184.

Opdebeeck, C., Martyr, A., Clare, L., 2016. Cognitive reserve and cognitive function in healthy older people: a meta-analysis. Aging Neuropsychol. Cogn. 23 (1), 40-60.

Parker, E.S., Cahill, L., McGaugh, J.L., 2006. A case of unusual autobiographical remembering. Neurocase 12 (1), 35-49.

Patihis, L., Frenda, S.J., LePort, A.K., Petersen, N., Nichols, R.M., Stark, C.E., McGaugh, J.L., Loftus, E.F., 2013. False memories in highly superior autobiographical memory individuals. Proc. Natl. Acad. Sci. U. S. A. 110 (52), 20947-20952.

Peavy, G.M., Salmon, D.P., Jacobson, M.W., Hervey, A., Gamst, A.C., Wolfson, T., Patterson, T.L., Goldman, S., Mills, P.J., Khandrika, S., Galasko, D., 2009. Effects of chronic stress on memory decline in cognitively normal and mildly impaired older adults. Am. J. Psychiatry 166 (12), 1384-1391.

Pezdek, K., Blandon-Gitlin, I., Gabbay, P., 2006. Imagination and memory: does imagining implausible events lead to false autobiographical memories? Psychon. Bull Rev. 13 (5), 764-769.

Pillemer, D., Wink, P., DiDonato, T., Sanborn, R., 2003. Gender differences in autobiographical memory styles of older adults. Memory 11 (6), 525-532.

Piolino, P., Desgranges, B., Eustache, F., 2000. La mémoire autobiographique: théorie et pratique. Solal, Marseille, France.

Piolino, P., Desgranges, B., Benali, K., Eustache, F., 2002. Episodic and semantic remote autobiographical memory in ageing. Memory 10 (4), 239-257.

Piolino, P., Desgranges, B., Clarys, D., Guillery-Girard, B., Taconnat, L., Isingrini, M., Eustache, F., 2006. Autobiographical memory, autonoetic consciousness, and selfperspective in aging. Psychol. Aging 21 (3), 510-525.

Piolino, P., Chételat, G., Matuszewski, V., Landeau, B., Mézenge, F., Viader, F., de La Sayette, V., Eustache, F., Desgranges, B., 2007. In search of autobiographical memories: a PET study in the frontal variant of frontotemporal dementia. Neuropsychologia 45 (12), 2730-2743.

Piolino, P., Desgranges, B., Eustache, F., 2009. Episodic autobiographical memories over the course of time: cognitive, neuropsychological and neuroimaging findings. Neuropsychologia 47 (11), 2314-2329.

Prebble, S.C., Addis, D.R., Tippett, L.J., 2013. Autobiographical memory and sense of self. Psychol. Bull. 139 (4), 815-840.

Prenderville, J.A., Kennedy, P.J., Dinan, T.G., Cryan, J.F., 2015. Adding fuel to the fire: the impact of stress on the ageing brain. Trends Neurosci. 38 (1), 13-25.

Prince, M.J., 2015. World Alzheimer Report 2015: the Global Impact of Dementia: an Analysis of Prevalence, Incidence, Cost and Trends. Alzheimer's Disease International, London.

Qin, S., Hermans, E.J., van Marle, H.J., Luo, J., Fernández, G., 2009. Acute psychological stress reduces working memory-related activity in the dorsolateral prefrontal cortex. Biol. Psychiatry 66 (1), 25-32.

Ramírez, E., Ortega, A.R., Chamorro, A., Colmenero, J.M., 2014. A program of positive intervention in the elderly: memories, gratitude and forgiveness. Aging Ment. Health 18 (4), 463-470.

Ramsøy, T.Z., Liptrot, M.G., Skimminge, A., Lund, T.E., Sidaros, K., Christensen, M.S. Baaré, W., Paulson, O.B., Jernigan, T.L., Siebner, H.R., 2012. Healthy aging attenuates task-related specialization in the human medial temporal lobe. Neurobiol. Aging 33 (9), 1874-1889.

Reuter-Lorenz, P.A., Cappell, K.A., 2008. Neurocognitive aging and the compensation hypothesis. Curr. Dir. Psychol. Sci. 17 (3), 177-182.

Ricarte, J.J., Latorre, J.M., Ros, L., Navarro, B., Aguilar, M.J., Serrano, J.P., 2011 Overgeneral autobiographical memory effect in older depressed adults. Aging Ment. Health 15 (8), 1028-1037.

Robbins, B.D., 2013. Enactive cognition and the neurophenomenology of emotion. In: Gordon, S. (Ed.), Neurophenomenology and Its Applications to Psychology. Springer, New York, pp. 1-24.

Ros, L., Latorre, J.M., Serrano, J.P., 2009. Working memory capacity and overgeneral autobiographical memory in young and older adults. Aging Neuropsychol. Cogn. 17 (1), 89-107.

Rubin, D.C., 2005. A basic-systems approach to autobiographical memory. Curr. Dir. Psychol. Sci. 14 (2), 79-83.

Särkämö, T., Tervaniemi, M., Laitinen, S., Numminen, A., Kurki, M., Johnson, J.K., Rantanen, P., 2014. Cognitive, emotional, and social benefits of regular musical activities in early dementia: randomized controlled study. Gerontologist 54 (4), 634-650.

Scates, S.K.H., Randolph, D.L., Gutsch, K.U., Knight, H.V., 1986. Effects of cognitivebehavioral, reminiscence, and activity treatments on life satisfaction and anxiety in the elderly. Int. J. Aging Hum. Dev. 22 (2), 141-146.

Schacter, D.L., Koutstaal, W., Norman, K. A, 1997. False memories and aging. Trends 
Cogn. Sci. 1 (6), 229-236.

Schneider, S., Brassen, S., 2016. Brooding is related to neural alterations during autobiographical memory retrieval in aging. Front. Aging Neurosci. 8.

Schrauf, R.W., Rubin, D.C., 1998. Bilingual autobiographical memory in older adult immigrants: a test of cognitive explanations of the reminiscence bump and the linguistic encoding of memories. J. Mem. Lang. 39 (3), 437-457.

Schrauf, R.W., Rubin, D.C., 2001. Effects of voluntary immigration on the distribution of autobiographical memory over the lifespan. Appl. Cogn. Psychol. 15 (7), S75-S88.

Serrano, J.P., Latorre, J.M., Gatz, M., Montanes, J., 2004. Life review therapy using autobiographical retrieval practice for older adults with depressive symptomatology. Psychol. Aging 19 (2), 272-277.

Serrano, J.P., Latorre, J.M., Gatz, M., 2007. Autobiographical memory in older adults with and without depressive symptoms. Int. J. Clin. Health Psychol. 7 (1), 41-57.

Shenhav, A., Botvinick, M.M., Cohen, J.D., 2013. The expected value of control: an integrative theory of anterior cingulate cortex function. Neuron 79 (2), 217-240.

Sitzer, D.I., Twamley, E.W., Jeste, D., 2006. Cognitive training in Alzheimer's disease: a meta-analysis of the literature. Acta Psychiatr. Scand. 114 (2), 75-90.

Snowden, J.S., Griffiths, H.L., Neary, D., 1996. Semantic-episodic memory interactions in semantic dementia: implications for retrograde memory function. Cogn. Neuropsychol. 13 (8), 1101-1139.

Spreng, R.N., Grady, C.L., 2010. Patterns of brain activity supporting autobiographical memory, prospection, and theory of mind, and their relationship to the default mode network. J. Cogn. Neurosci. 22 (6), 1112-1123.

Spreng, R.N., Mar, R.A., Kim, A.S., 2009. The common neural basis of autobiographical memory, prospection, navigation, theory of mind, and the default mode: a quantitative meta-analysis. J. Cogn. Neurosci. 21 (3), 489-510.

Spreng, R.N., Lockrow, A.W., DuPre, E., Setton, R., Spreng, K.A., Turner, G.R., Semanticized autobiographical memory and the default-executive coupling hypothesis of aging. Neuropsychologia. (in press) https://dx.doi.org/10.1016/j. neuropsychologia.2017.06.009.

St Jacques, P.L., 2012. Functional neuroimaging of autobiographical memory. In: Bernsten, D., Rubin, D.C. (Eds.), Understanding Autobiographical Memory. Cambridge University Press, Cambridge, UK, pp. 114-138.

Stopford, C.L., Thompson, J.C., Neary, D., Richardson, A.M., Snowden, J.S., 2012. Working memory, attention, and executive function in Alzheimer's disease and frontotemporal dementia. Cortex 48 (4), 429-446.

Subramaniam, P., Woods, B., Whitaker, C., 2014. Life review and life story books for people with mild to moderate dementia: a randomised controlled trial. Aging Ment. Health 18 (3), 363-375.
Svoboda, E., McKinnon, M.C., Levine, B., 2006. The functional neuroanatomy of autobiographical memory: a meta-analysis. Neuropsychologia 44 (12), 2189-2208.

Tang, Y.Y., Hölzel, B.K., Posner, M.I., 2015. The neuroscience of mindfulness meditation. Nat. Rev. Neurosci. 16 (4), 213-225.

Thompson, R.G., Moulin, C.J.A., Hayre, S., Jones, R.W., 2005. Music enhances category fluency in healthy older adults and Alzheimer's disease patients. Exp. Aging Res. 31 (1), 91-99.

Varela, F.J., 1996. Neurophenomenology: a methodological remedy for the hard problem. J. Conscious. Stud. 3 (4), 330-349.

Volkow, N.D., Gur, R.C., Wang, G.J., Fowler, J.S., Moberg, P.J., Ding, Y.S., Hitzemann, R. Smith, G., Logan, J., 1998. Association between decline in brain dopamine activity with age and cognitive and motor impairment in healthy individuals. Am. J. Psychiatry 155 (3), 344-349.

VonDras, D.D., Powless, M.R., Olson, A.K., Wheeler, D., Snudden, A.L., 2005. Differential effects of everyday stress on the episodic memory test performances of young, midlife, and older adults. Aging Ment. Health 9 (1), 60-70.

Wang, J.J., 2005. The effects of reminiscence on depressive symptoms and mood status of older institutionalized adults in Taiwan. Int. J. Geriatr. Psychiatry 20 (1), 57-62.

Webster, J.D., Cappeliez, P., 1993. Reminiscence and autobiographical memory: complementary contexts for cognitive aging research. Dev. Rev. 13 (1), 54-91.

Whalley, L.J., Deary, I.J., Appleton, C.L., Starr, J.M., 2004. Cognitive reserve and the neurobiology of cognitive aging. Ageing Res. Rev. 3 (4), 369-382.

Williams, J.M., Broadbent, K., 1986. Autobiographical memory in suicide attempters. J. Abnorm. Psychol. 95 (2), 144-149.

Wilson, A., Ross, M., 2003. The identity function of autobiographical memory: time is on our side. Memory 11 (2), 137-149.

Winocur, G., Moscovitch, M., Bontempi, B., 2010a. Memory formation and long-term retention in humans and animals: convergence towards a transformation account of hippocampal-neocortical interactions. Neuropsychologia 48 (8), 2339-2356.

Winocur, G., Moscovitch, M., Rosenbaum, R.S., Sekeres, M., 2010b. A study of remote spatial memory in aged rats. Neurobiol. Aging 31 (1), 143-150.

Woods, R.T., Orrell, M., Bruce, E., Edwards, R.T., Hoare, Z., Hounsome, B., Keady, J., Moniz-Cook, E., Orgeta, V., Rees, J., Russell, I., 2016. REMCARE: pragmatic multicentre randomised trial of reminiscence groups for people with dementia and their family carers: effectiveness and economic analysis. PLoS One 11 (4), e0152843.

World Health Organization,, 2017. Depression and Other Common Mental Disorders: Global Health Estimates. World Health Organization, Geneva.

Young, L.A., Baime, M.J., 2010. Mindfulness-based stress reduction: effect on emotional distress in older adults. Complement. Health Pract. Rev. 15 (2), 59-64. 